\title{
CONTRATOS DEL SECTOR PÚBLICO Y DERECHO DE LA UNIÓN
}

\author{
Juan Alfonso Santamaría Pastor \\ Catedrático de Derecho Administrativo \\ Universidad Complutense de Madrid
}

\begin{abstract}
RESUMEN
El trabajo persigue analizar las características de la normativa de contratos derivadas de la paulatina aplicación de las Directivas de la Unión Europea. Examina los rasgos externos de dicha normativa, las más importantes de las innovaciones introducidas de entre las que merecen una crítica por su escasa fortuna, y pretende evaluar el nivel de consecución de los objetivos que las reformas legales han pretendido.

Palabras clave: contratos públicos; directivas comunitarias; ámbito de la legislación; contratos típicos; recursos contractuales; corrupción; agilización de los procedimientos.
\end{abstract}

\begin{abstract}
The paper aims to examine and explore the characteristics of contracting regulations resulting from the gradual implementation of European Union Directives. It analyses the external features of said regulations, the most important innovations introduced amongst those which warrant criticism for their unsuccessful outcome and intends to assess the achievement rate for the objectives sought by these legal reforms.
\end{abstract}

Key words: public procurement; EU directives; scope of legislation; standard agreements; contractual appeals; corruption; streamlining of procedures. 


\section{SUMARIO}

I. LOS RASGOS EXTRÍNSECOS DE LA NORMATIVA: 1. El crecimiento de las dimensiones físicas de los textos legales y su reglamentismo. 2. La inestabilidad regulatoria. 3 . Contenido predominantemente procedimental. 4. Las causas.-II. LAS MODIFICACIONES SUSTANTIVAS: 1. El ámbito subjetivo de la legislación. 2. El incremento de los contratos administrativos típicos. 3. Los medios de publicidad. 4. Los intentos de negar la evidencia: revisión de precios, modificación de los contratos y bajas temerarias. 5. El sistema de tribunales y recursos contractuales.-III. Los oBJETIVos PERSEGUIDOS Y SU FRACASO: 1. El objetivo del mercado único. 2. La lucha contra la corrupción. 3. La unificación de las legislaciones. 4. La agilización de los procedimientos.-IV. CONCLUSIón.

Hacía mucho tiempo que no releía de corrido el texto de nuestra primera ley de contratos, de cuya inserción en el Boletín Oficial del Estado se cumplen hoy, casualmente, cincuenta y un años ${ }^{1}$. Hube de hacerlo para localizar las huellas que el paso del tiempo y la incidencia de la incorporación de España al sistema comunitario han dejado en el aún vigente texto refundido de 2011²; y este rápido examen hubo de extenderse, después, a los tres textos generales que han estado en vigor en el intervalo entre los antes mencionados (la Ley 13/1995, de 18 de mayo, de Contratos de las Administraciones Públicas, el Texto Refundido de la misma, aprobado por Real Decreto Legislativo 2/2000, de 16 de junio, y la Ley 30/2007, de 30 de octubre, de Contratos del Sector Público). Una labor fatigosa, pero imprescindible para comprobar cómo, por qué y hacia dónde ha evolucionado nuestro derecho de la contratación pública.

1 Texto articulado de la Ley de Contratos del Estado, aprobado por Decreto 923/1965, de 8 de abril. Su publicación tuvo lugar el 23 de abril siguiente.

2 En lo sucesivo, TRLCSP. A fecha de hoy, esta disposición debería haber sido ya sustituida por la nueva Ley mediante las que se transpusieran a nuestro ordenamiento las Directivas 23 , 24 y 25 de 2014 (su plazo expiró el pasado 18 de abril). Y, aunque el anteproyecto de Ley se encuentra ya elaborado (accesible en http://www.minhap.gob.es/Documentacion/Publico/NormativaDoctrina/Proyectos/Borrador\%20Anteproyecto $\% 20 \mathrm{de} \% 20 \mathrm{Ley} \% 20 \mathrm{de} \% 20$ Contratos $\% 20$ del $\% 20$ Sector $\% 20$ P\%C3\%BAblico-\%2017\%20abril\%202015.pdf), la peculiar situación política en que se halla el país, encaminado a una segunda convocatoria de elecciones generales, no hace previsible que la nueva Ley sea aprobada antes de finalizar el presente año; y esto, con suerte. Por ello, las referencias que se hacen en este trabajo al derecho vigente lo serán al citado texto refundido.

Es cierto que parte de las nuevas Directivas debe considerarse ya en vigor, por su efecto directo (véase, sobre ello, la Recomendación de la Junta Consultiva de Contratación Administrativa de 15 de marzo de 2016, BOE de 17 de marzo). Pero en el nivel de generalidad en el que se mueve este trabajo, las valoraciones que se hacen en él a propósito del TRLCSP son prácticamente aplicables al texto del Anteproyecto. 
Esta evolución no difiere excesivamente de la que han sufrido otros sectores del ordenamiento administrativo. Ha sido especialmente intensa en lo que podríamos llamar sus rasgos extrínsecos, que en este caso poseen mayor importancia de lo que su naturaleza formal podría hacer pensar (I); la regulación sustantiva de las instituciones del régimen contractual ha experimentado, también, modificaciones importantes de las que conviene dejar constancia, pero que no han supuesto un cambio radical de perspectiva en casi ningún caso (II). Y, a la vista de una y otra circunstancia, es obligado preguntarse cuáles han sido los objetivos de esta evolución y en qué medida han quedado satisfechos (III).

\section{LOS RASGOS EXTRÍNSECOS DE LA NORMATIVA}

1. El crecimiento de las dimensiones físicas de los textos legales y su reglamentismo

El primer dato que salta a la vista en la normativa de contratos radica en el crecimiento exponencial de las dimensiones físicas de los textos legales: la Ley de 1965, en el texto que presentaba inmediatamente antes de su derogación por la Ley 13/1995, tenía 125 artículos, tamaño que contrasta con los 331 que posee el TRLCSP en la actualidad (tras la derogación de tres de sus preceptos en materia de revisión de precios). Y no sólo ha aumentado el número de los artículos, sino sobre todo la dimensión de cada uno de éstos, que puede fácilmente medirse con una de las utilidades de Word: de acuerdo con los datos que este programa arroja, el TRLCSP viene a ser 6,3 veces mayor, en número de caracteres, que la Ley de $1965^{3}$.

Este incremento físico es, en parte, imputable a la incorporación a la Ley de preceptos antes contenidos en sus reglamentos de ejecución, pero también a un desarrollo mucho más minucioso de sus prescripciones: el TRLCSP es, en efecto, una disposición de un detallismo reglamentista realmente abrumador. Esta directriz, que ha minimizado el papel de las normas reglamentarias, no parece basarse en un respeto escrupuloso del principio de reserva de ley (muchos - la mayoría- de sus artículos o apartados tienen un contenido puramente secundario). Antes bien, es

3 La desproporción de tamaño no varía sensiblemente sumando a los preceptos de la Ley de 1965 los 393 artículos de que constaba su voluminoso Reglamento General (el segundo, aprobado por Decreto 3410/1975, de 25 de noviembre), cuyas dimensiones son engañosas, ya que su texto reproducía la totalidad de los preceptos de la Ley que desarrollaba. En conjunto, y para ser precisos, puede decirse que el tamaño del TRLCSP viene a ser más de tres veces el que poseían la Ley de 1965 y su Reglamento. 
una muestra más, entre otras muchas, de un rasgo muy característico de nuestro ordenamiento administrativo de los últimos lustros, que tiene a una «legalización» sistemática de las regulaciones en perjuicio de la colaboración reglamentaria. No cabe despreciar la idea de que con ello se busque un mayor nivel de inmunidad de los contenidos de las normas frente a las impugnaciones de que puedan ser objeto en vía contenciosa.

Pero, sea cual fuere su intencionalidad, los inconvenientes de este exacerbado detallismo son evidentes. Con esta contextura, el aprendizaje e interiorización de la Ley por todos sus aplicadores se dificulta sobremanera, propiciando sus infracciones involuntarias; lo cual no solo perjudica el exacto cumplimiento de la Ley, sino que puede tener consecuencias imprevistas y sumamente graves en los momentos actuales, en los que la vulneración de cualquiera de las normas relativas a las licitaciones puede dar lugar a la inmediata apertura de diligencias penales contra el funcionario o cargo público responsable y contra el licitador o contratista supuestamente beneficiado por aquellas infracciones.

\section{La inestabilidad regulatoria}

Estas disfunciones se ven incrementadas por una segunda circunstancia, la inestabilidad regulatoria, cuyo ritmo se ha intensificado con el tiempo. En los treinta años que la Ley de 1965 tuvo de vigencia, solo fueron modificados 28 de sus artículos: un tempo claramente moderato. Pero, a partir de la aprobación de la Ley de 1995, la cadencia de las modificaciones sufrió una aceleración brutal: en sus cinco años de vigencia (hasta el texto refundido de 2000), la Ley fue objeto de modificación en más de la mitad de sus artículos (121 sobre 219); el texto refundido de 2000 estuvo en vigor, hasta su sustitución por la Ley 30/2007, siete años, durante los cuales se modificaron 48 de sus artículos; la Ley 30/2007 hubo de ser objeto de refundición solo cuatro años después de su aprobación, al haber sido modificados 77 de sus artículos; y el TRLCSP experimentó, en los cuatro años siguientes a su entrada en vigor (hasta las elecciones generales de 20 de diciembre de 2015), reformas en nada menos que 63 de sus artículos y disposiciones adicionales y transitorias.

No creo que haya una legislación, en todo nuestro ordenamiento jurídico, comparable en volatilidad a la normativa básica de contratos. La inmensa mayoría de estas modificaciones no trae causa de la necesidad de incorporar reformas del derecho comunitario: se trata de improvisaciones privativas del legislador español, normalmente ten- 
dentes a la solución de problemas específicos, en la mejor tradición de las leyes-medida; por más que, en el último caso, algunas de ellas puedan estar justificadas por la profunda crisis económica que hemos padecido ${ }^{4}$.

Las disfunciones generadas por la inestabilidad regulatoria son, en algún caso, evidentes: intensifica las dificultades de conocimiento del derecho positivo y potencia la comisión de vulneraciones al mismo, por no hablar de la desesperación que crea al colectivo de juristas. Pero sus efectos perversos van mucho más allá: de una parte, constituye un factor de desincentivación de los inversores potenciales, una de cuyas principales preocupaciones, si no la más importante, es el nivel previsible de estabilidad de las regulaciones y del comportamiento de los tribunales. $\mathrm{Y}$, de otra, tiene un impacto absolutamente imprevisto en el esquema constitucional de división de poderes: en un escenario de normalidad institucional, las leyes son aprobadas por los parlamentos, y su contenido comienza a hacerse realidad cuando son aplicadas durante un tiempo por los tribunales, cuyas sentencias, con mejor o peor fortuna, proporcionan los elementos interpretativos necesarios para completar y hacer inteligible su significado. El cambio normativo elimina la segunda de estas dos piezas, al Poder Judicial, cuya demora en la resolución de los conflictos le impide sentar doctrina sobre las disposiciones vigentes en el momento de su fallo.

\section{Contenido predominantemente procedimental}

La tercera característica extrínseca de la legislación de contratos, a lo largo de toda su evolución, consiste en su contenido predominantemente procedimental. Un jurista desconocedor de esta legislación podría suponer, seguramente, que una ley de contratos debe consistir en un conjunto de preceptos referidos a cuestiones similares a las que regula el Código Civil. Pero tales cuestiones son, en el conjunto, una estruendosa minoría: el TRLCSP es, en su práctica totalidad, un enorme reglamento de procedimiento administrativo relativo a la licitación y adjudicación de los contratos celebrados por los entes públicos; y una norma, además, que huye deliberadamente de la aplicación de la Ley 30/1992 (aún

\footnotetext{
${ }^{4}$ Por no mencionar más que un supuesto: la adición del nuevo apartado 7 al artículo 271 responde, sin duda, a los problemas derivados de la imperativa subrogación del Estado en la obligación de abonar los justiprecios expropiatorios generados por la construcción de las autopistas radiales de Madrid, cuyas empresas concesionarias entraron en concurso y posterior liquidación.
} 
vigente en este momento), a la que sólo se otorga eficacia supletoria ${ }^{5}$, y algunas de cuyas reglas básicas se rechazan expresamente ${ }^{6}$.

\section{Las causas}

En el origen de todas estas características - y de los problemas creados por ellas - se encuentran dos factores de imprescindible alusión. En primer lugar, la mentalidad hacendística que rebosan las sucesivas leyes, todos cuyos proyectos fueron objeto de elaboración en los servicios de ese departamento ministerial. Al hablar de tal mentalidad me refiero a la tendencia obsesiva de las autoridades financieras a considerar a todos los departamentos inversores, sin excepción, como pésimos administradores de los fondos públicos y como corruptos en potencia. Esta actitud es, por así decir, transversal: se da en todas las organizaciones, públicas y privadas; los controller financieros de todas las organizaciones se comportan exactamente de la misma manera, y tienden a complejificar ad infinitum las cautelas procedimentales tendentes a reducir el gasto y a atar corto a los que tienen la responsabilidad de comprometer los recursos; una obsesión que no sólo se debe a un rigor calvinista en el manejo de los fondos, sino también al deseo de incrementar cuotas de poder en la organización respectiva. Comprendo esta preocupación —es realmente muy duro desempeñar el papel de recaudador y administrador de unos fondos que siempre son escasos-, y aludo a esta mentalidad, por ello, sin voluntad alguna de censura; pero, por justificada que sea, sus consecuencias negativas están ahí.

La normativa comunitaria tampoco es ajena a la producción de estas disfunciones. Por más que esta constatación sea escandalosa para algunos, es necesario señalar que las sucesivas Directivas en materia de contratos, empezando por las más antiguas, constituyen un palmario exceso competencial de las instituciones comunitarias. Todas ellas han invocado, invariablemente, el título de la libertad de establecimiento para explicar su aprobación: un título notoriamente insuficiente. La libertad de establecimiento amparaba, desde luego, la emisión de normas dirigidas a evitar las restricciones a la participación de empresas comunitarias en las licitaciones públicas, y cualquier otra medida equi-

\footnotetext{
${ }^{5}$ Hay en el TRLCSP tres únicas remisiones a la normativa de procedimiento administrativo común; todas ellas, en la regulación del recurso especial en materia de contratación (arts. $40.5,41.1$ y 44.5).

6 Así, la regla general de silencio positivo (Disposición Final 3. ${ }^{a}$ ) y el cómputo de los plazos en días naturales (Disposición Adicional Duodécima).
} 
valente que resultase discriminatoria; pero en absoluto podía dar cobijo a las numerosas disposiciones reguladoras del régimen procedimental y sustantivo de los contratos, que son aplicables por igual a licitadores nacionales y extranjeros y que ninguna incidencia tienen en la citada libertad de establecimiento. Se mire por donde se mire, la normativa comunitaria de contratos no es, salvo en una parte mínima, un conjunto de medidas que asegure o favorezca la creación de un mercado único de compras públicas, sino una auténtica legislación uniforme en una materia en la que la Unión carecía y carece de toda competencia. Solo las profundas diferencias que existen entre los Estados miembros, en la regulación de sus procedimientos administrativos, han determinado que las instituciones hayan seguido empleando la forma jurídica de Directiva, en lugar de utilizar resueltamente la de reglamento ${ }^{7}$.

No es infrecuente (en España tenemos abundantes muestras de ello) que cuando una organización pública dicta una normativa sobre la que ostenta una competencia dudosa, y cuya aplicación práctica es menos que satisfactoria, reaccione intensificando la cantidad y el detalle de las disposiciones dirigidas al mismo fin. Los números cantan: la Directiva 71/305/ CEE, sobre contratos de obras, ocupaba 10 páginas en el DOUE; y la Directiva 93/37/CEE, que la sustituyó, 30. La Directiva 77/62/CEE, sobre contratos de suministro, tenía 14 páginas en su publicación; y la 93/36/CEE, que ocupó su lugar, 53. La Directiva 2004/18/CE superó notoriamente a todas ellas, con sus 127 páginas de texto. Y el paquete constituido por las tres Directivas 23, 24 y 25/2014/UE, finalmente, ocupa 374 páginas.

\section{LAS MODIFICACIONES SUSTANTIVAS}

Esta hipercompleja normativa comunitaria ha provocado también, como era de esperar, modificaciones sustanciales, de detalle y de contenido, en la práctica totalidad de las instituciones que integran el régimen jurídico de los contratos públicos. Dadas las dimensiones predeterminadas que ha de tener esta colaboración, es obviamente imposible mencionar siquiera a todas ellas. Habré de limitarme a las que me parecen, desde el punto de vista práctico, más relevantes y más susceptibles de crítica.

7 Como ha sucedido, también sin título competencial suficiente, en otras materias. Sirva el ejemplo de la protección de datos, campo en el que la norma hasta hace bien poco vigente (la Directiva 95/46/CE del Parlamento Europeo y del Consejo, de 24 de octubre de 1995) ha sido derogada y sustituida por el reciente Reglamento (UE) 2016/679, del Parlamento Europeo y del Consejo, de 27 de abril de 2016 (DOUE de 4 de mayo de 2016). 


\section{El ámbito subjetivo de la legislación}

Sobre el peculiar artículo 3 del TRLCSP se ha escrito ya casi todo, frecuentemente en sentido crítico. Pero, en justicia, estas críticas solo pueden ser dirigidas exclusivamente a la normativa comunitaria en lo que se refiere a su apartado 3 y a la noción de poderes adjudicadores, única a la que se refiere la Directiva 2004/18/CE (artículo 1.9); los dos apartados anteriores son, por así decirlo, cosecha del legislador nacional, que pretendió someter a disciplina contractual a la totalidad de los entes integrantes de lo que denomina sector público.

No es mi pretensión, ni cabría en un ensayo de esta naturaleza, insistir en la discusión acerca del contenido del concepto de poder adjudicador, sobre el que ha recaído una doctrina de imposible cita, por abundante. Me limito a formular dos censuras a esta norma, por más polémicas que resulten.

a) En primer término, el empleo de esta tripartición de entidades - que en buena parte se solapan — da lugar a dificultades interpretativas constantes, referidas a la determinación de los preceptos del TRLCSP que son aplicables a unas y otras. El texto refundido, en efecto, indica en algunos casos, al regular una materia concreta, si las normas correspondientes se aplican a todos los entes del sector público, solo a las Administraciones públicas, sólo a los poderes adjudicadores o a varios de ellos a la vez ${ }^{8}$; pero, en otros muchos casos, guarda silencio, dejando en la indefinición qué categorías de entidades se hallan sujetas a los respectivos preceptos.

b) Muy distinto es el reproche que debe hacerse al desmedido afán de la legislación de contratos - y, en un grado sólo algo menor, de la normativa comunitaria y de la jurisprudencia del Tribunal de Justicia- por someter a la disciplina de contratos públicos a todo tipo de entidades más o menos conectadas o dependientes de las Administraciones territoriales ${ }^{9}$. Sé que opino aquí a contrapelo de la doctrina administrativa, que, de modo prácticamente unánime, hizo bandera de esta aplicación universal de la legislación de contratos al hilo de la campaña contra la huida del derecho administrativo; pero, aunque la discrepancia sea

8 Así, declaran su aplicación a todos los contratos celebrados por entes del sector público (artículo 3.1) los artículos 23, 25.1, 26.1, 54.1, 62.1, 86.1, 87.1, 89.1 y 5, 105.1, 106, DA 7. a; a los contratos que celebren las Administraciones públicas, los artículos 28.2, 31, 34.1, 40.1, 65.1, 87.3 y $7,95.1,96.1,109.1,138.1,142.1,156.1,159.2,170$ y $175 ;$ y, a los contratos celebrados por entes calificados de poderes adjudicadores, los artículos 24.6, 27.1, 38.3, 137, 189 a 191 y DA 36. .

${ }^{9}$ Una tendencia que el Anteproyecto de 2015 mantiene, al incluir en el ámbito de aplicación de la Ley a los partidos políticos, las organizaciones sindicales y empresariales (así como a las fundaciones y asociaciones vinculadas a cualquiera de ellos, cuando cumplan los requisitos para ser poder adjudicador) y a las Corporaciones de Derecho Público (artículo 3.4 y 5). 
inútil, no puedo dejar de expresar mi opinión de que la tan censurada proliferación de entes atípicos y con forma de derecho privado que tiempos atrás se crearon con objeto de contratar con la agilidad propia de una empresa privada tenía bastante de razonable, porque intentar realizar actividades económicas en el mercado y someterse a los requisitos de contratación que pesan sobre las Administraciones públicas es una inconsecuencia; más aún cuando los efectos, la ejecución y la extinción de los contratos celebrados por algunas de estas entidades se califican de derecho privado, despojando a los entes públicos respectivos de los poderes de autoridad que requiere su actuación (el caso de las entidades públicas empresariales es, en este orden de cosas, paradigmático).

\section{El incremento de los contratos administrativos típicos}

Otro efecto patente de la normativa comunitaria ha sido el aumento del número de contratos sometidos de lleno a la disciplina de la contratación pública. A la tríada clásica de contratos que figuraba en la Ley de 1965 se han añadido sucesivamente los de concesión de obra pública, de servicios ${ }^{10}$ y de colaboración entre el sector público y el sector privado ${ }^{11}$.

La tipificación de nuevos contratos no genera problema alguno, obviamente; más bien al contrario. Las dificultades provienen del carácter básicamente procedimental de la regulación que se establece para ellos, que es sustancialmente distinta en cada caso. Ello determina que cada contrato se configure como un constructo cerrado, que obliga al gestor público a optar imperativamente entre una y otra modalidad, sin posibilidad de error; lo cual es particularmente espinoso en muchas ocasiones, ya que los límites entre unos contratos y otros son frecuentemente impalpables, como demuestra, por ejemplo, los laboriosos esfuerzos doctrinales por distinguir entre el contrato de servicios y el de gestión de servicios públicos, o entre determinados contratos de concesión de obra pública y el de colaboración público/privado.

A ello han de añadirse las dificultades que suscitan los contratos mixtos (por ejemplo, los de gestión de servicios públicos con ejecución de obra), ya que el tosco criterio que apunta el artículo 12 del TRLCSP para

10 Que, como es sabido, ya había sido creado, de modo casi subrepticio, por el Decreto 1005/1974, de 4 de abril, con el nombre de contratos de asistencia con empresas consultoras o de servicios.

11 Que desaparecerá, previsiblemente, en la nueva ley: véase el párrafo cuarto, epígrafe IV de la exposición de motivos. El texto no ofrece explicación alguna de esta supresión, seguramente por ser innecesaria, dada la escasísima utilización que se ha hecho de este tipo de contrato. 
determinar las reglas de adjudicación aplicables es, muchas veces, de aplicación incierta, puesto que determinar «la prestación que tenga más importancia desde el punto de vista económico» no es, sencillamente, factible en muchos casos.

Estas dificultades podrían minimizarse, a mi juicio, si en lugar de tipificar contratos como mundos cerrados, se regulasen las reglas procedimentales pertinentes por tipos de prestaciones contratadas, permitiendo a los entes públicos diseñar discrecionalmente el contenido de dichas prestaciones; como se hace habitualmente y sin problema alguno en el derecho privado.

\section{Los medios de publicidad}

Todo sistema de contratos públicos digno de tal nombre debe atender a asegurar la transparencia y el acceso público a la información relativa a la actividad contractual. En esta línea, nuestra legislación (impelida por la normativa comunitaria: en este caso, felizmente) ha experimentado sensibles progresos, fundamentalmente con la creación de los nuevos instrumentos del perfil de contratante y de la Plataforma de Contratación del Estado (artículos 53 y 334 del TRLCSP); aunque, quizá como un tributo al pasado, se ha decidido mantener la publicación en diarios oficiales como soporte de tales informaciones, cuya eficacia difusora es cada día más limitada. La regulación de esta importante mejora es susceptible, no obstante, de algunas censuras.

a) En primer lugar, la que puede hacerse al inexplicable respeto al principio de pluralidad y dispersión. El artículo 53.1 del TRLCSP dispone que «los órganos de contratación difundirán, a través de Internet, su perfil de contratante»; dicho de manera más directa, cada órgano de contratación dispone de su propio perfil, lo que supone, desde el punto de vista del interesado, la necesidad de consultar diariamente docenas de perfiles en otras tantas páginas web para encontrar información de interés sobre nuevas licitaciones. Hubiera sido mucho más razonable imponer que todos los perfiles de contratante de cada una de las Administraciones públicas se integraran en una única plataforma de contratación (como, de facto, han hecho algunas comunidades autónomas, como Cataluña, Asturias, Canarias, País Vasco y La Rioja).

b) Algo semejante ha de decirse, en el mismo sentido, acerca de la configuración que el artículo 334 del TRLCSP dio a la Plataforma de Contratación del Estado, que sólo integra obligatoriamente los perfiles 
de contratante de los órganos de contratación del sector público estatal; respecto de los correspondientes a las restantes Administraciones, el texto refundido, en un absurdo respeto a la autonomía, establece tal integración como puramente voluntaria («La Junta Consultiva de Contratación Administrativa del Estado [...] pondrá a disposición de todos los órganos de contratación del sector público una plataforma electrónica...»); una tímida invitación que sólo ha sido acogida por las cinco comunidades autónomas que mencionamos en el párrafo anterior. No nos parece que atente a la autonomía de ningún tipo de ente público que los perfiles o plataformas de todas las Administraciones se encuentren obligatoriamente integradas en la Plataforma estatal, sin perjuicio de que cada una de ellas pueda disponer de su perfil de contratante o plataforma propios, si lo estima oportuno.

c) Y esta falta de unificación de la información contractual tiene su origen en la imprevisión de la normativa de contratos acerca de una cuestión (aparentemente secundaria, pero fundamental desde el punto de vista de la publicidad), cual es la homogeneización del formato de las páginas web en las que se alojan los perfiles de contratante, cada uno de las cuales es distinto; lo que hace muy laboriosa - por no decir que desesperante en ocasiones - la búsqueda de la información deseada, y dificulta en extremo la integración en una plataforma única. Y, en el mismo sentido, no sería impertinente que se produjera un acuerdo entre las distintas Administraciones territoriales en cuanto a la localización del perfil o plataforma de contratación dentro de la web principal de cada Administración: en no pocas de ellas, el link correspondiente se encuentra cuidadosamente disimulado entre un batiburrillo de informaciones festivas o laudatorias de la actividad pro cive de los respectivos gobiernos.

4. Los intentos de negar la evidencia: revisión de precios, modificación de los contratos y bajas temerarias

En esta fugaz enumeración de innovaciones de escasa fortuna, inducidas por la normativa comunitaria, no puede faltar una referencia (que, lamentablemente, ha de ser muy breve) a tres reformas mediante las cuales el legislador, preso de un irresistible voluntarismo, intenta modificar una realidad que se impone con la fuerza de las cosas. Nos atrevemos a pronosticar que sin éxito alguno.

a) El régimen de la revisión de precios y de la modificación de los contratos ha sido objeto de sendas modificaciones por la Ley 2/2015, 
de 30 de marzo, de desindexación de la economía española y por la Ley 2/2011, de 4 de marzo, de Economía Sostenible, respectivamente; en ambos casos, en un sentido fuertemente restrictivo y bajo la suposición de que ambas técnicas no son otra cosa que pretextos para falsear la autenticidad de las proposiciones.

Es innegable que estas anomalías han tenido lugar en no pocos casos; pero no es menos cierto que la revisión de los precios de un contrato y su modificación son medios indispensables para que la ejecución de los contratos se desarrolle en términos razonables. Las restricciones que el nuevo artículo 89 del TRLCSP impone a la revisión de precios son un típico producto voluntarista, idéntico al que regía esta institución antes del ya olvidado Decreto Ley de 1964, y solo comprensible en una etapa histórica como la que vivimos, de recesión profunda y de mantenimiento o caída generalizada de los precios; pero estas pretensiones se revelarán insostenibles en el momento en que la economía mundial recupere la senda inflacionista que le ha caracterizado desde principios del siglo xIX; porque no hay crecimiento económico posible sin alza de precios, que llegará.

b) Algo muy similar ha de decirse de las fuertes limitaciones impuestas a la modificación de los contratos por los artículos 105 a 108 del TRLCSP. Es una muestra de enternecedora inocencia la previsión de que los contratos "sólo podrán modificarse cuando así se haya previsto en los pliegos o en el anuncio de licitación» (artículo 105.1): salvo supuestos excepcionales, ningún órgano de contratación confiesa en la convocatoria que su proyecto adolece de defectos o que no está seguro de su contenido, por si acaso ha de modificarse. Pero es que, además (y siempre dejando a un lado los supuestos de fraude), las modificaciones de los contratos responden invariablemente a circunstancias imprevisibles, cuando no a los cambios de criterio, no siempre caprichosos, de los promotores políticos de la obra o servicio.

c) Y muestra también una acusada carencia de realismo la complacencia que ahora se muestra hacia las ofertas que incurren en bajas temerarias (artículo 152). El requisito de que la apreciación de tales bajas exige su previsión en los pliegos es difícilmente defendible en una situación de apuro económico endémico de las Administraciones, como la presente: hacer tal previsión tiene el riesgo de ser interpretado como una renuncia a obtener precios de mercado favorables. Y permitir que el licitador cuya oferta presenta estas características justifique por escrito los valores anormales que ofrece es una previsión tan aparentemente razonable como inútil, porque el papel lo aguanta todo, y hay que ser muy poco hábil para no poder aportar una explicación muy aseada; que 
suele ser infundada, porque, en la actualidad, los costes de las empresas se mueven dentro de unos márgenes tan estrechos como similares. $\mathrm{Si}$, en aras del ahorro, se acepta la posibilidad de adjudicar los contratos a ofertas con valores anormalmente bajos, no cabe otra alternativa que completar tal previsión con la prohibición tajante de que dicho contrato sea objeto de ningún tipo de revisión de precios o modificación ulterior; algo que la Ley, inexplicablemente, no establece.

Las Administraciones no deberían olvidar nunca una frase que hace muchos años escuché al profesor Jordana de Pozas, y que él atribuía a don Recaredo Fernández de Velasco: no soy lo bastante rico para comprar muy barato.

\section{El sistema de tribunales y recursos contractuales}

Las consideraciones que se vierten en este breve trabajo pudieran dar la impresión de que el autor no encuentra un solo hombre justo en esta aparente Sodoma y Gomorra de la legislación de contratos. Ello es solo imputable a las limitaciones que el Consejo de Redacción de la revista impuso a los colaboradores de este número, que nos obliga a ceñirnos a aquellas cuestiones más dignas de crítica, dejando a un lado las regulaciones que, impuestas por la normativa comunitaria, merecen una valoración positiva; no me duele omitirlas, ya que han sido puestas de relieve en muchas ocasiones, por la doctrina española, a la que caracteriza habitualmente un encendido tono hagiográfico hacia dichas regulaciones.

Creo obligado, no obstante, hacer una excepción para referirme al nuevo sistema de revisión en vía administrativa de las licitaciones: me refiero, naturalmente, al régimen de recursos administrativos especiales y a los órganos creados para su resolución. He dedicado a unos y otros una pequeña obra ${ }^{12}$ que, como todo libro, se encuentra en nuestros días condenado al olvido, porque no se encuentra colgado en la red. Y, dada la mayor difusión que es previsible tenga este número conmemorativo, no me parece ilícito reiterar aquí algunas de las valoraciones que hice en él.

La creación e implantación de este nuevo sistema ha de considerarse un acierto, pese a la resistencia numantina que el legislador español opuso a la transposición de las Directivas 89/665/CEE, 92/13/CEE y 2007/66/CE, sólo doblegada tras las sucesivas condenas al Reino de

12 J. A. SANTAMaría PAStor (2015), Los recursos especiales en materia de contratos del sector público, Cizur Menor: Aranzadi. 
España dictadas por el Tribunal de Luxemburgo ${ }^{13}$. Pero lo cierto es que, a fin de cuentas, la regulación del sistema de recursos, establecido por la Ley 34/2010, de 5 de agosto, ha mejorado incluso los principios impuestos por las Directivas antes citadas, que son una perfecta combinación de magníficas intenciones y de una pésima técnica normativa.

El éxito que ha tenido esta nueva institución es un parecer compartido, en lo que me consta, por la totalidad de los juristas que nos dedicamos a estos menesteres, pero también por la mayoría de las empresas licitadoras, con independencia del resultado favorable o no de los recursos en los que han sido parte. El tiempo de resolución de los recursos especiales está siendo, hasta la fecha, insólitamente breve (y, en muchos casos, incluso ajustado a los brevísimos plazos que establecen los artículos 43 y siguientes del TRLCSP); el contenido de las resoluciones, harto solvente en su fundamentación, lo que lleva a un porcentaje de impugnaciones de las mismas en vía contenciosa anormalmente reducido; y, sobre todo, el fallo de los recursos, con un índice muy digno de estimaciones, acredita que la independencia de los tribunales administrativos y órganos de resolución no es una declaración vacía de contenido. Hasta el momento, pues, el sistema tiene un comportamiento ejemplar, que ha desmentido las previsiones negativas que muchos abrigaban, incluido el autor de estas líneas.

Es cierto que buena parte del éxito de esta innovación se debe a circunstancias de hecho, ajenas a su regulación: de una parte, al acierto en la selección de los funcionarios que integran los tribunales administrativos —que, inesperadamente, no se basó en criterios de afinidad política-y al empeño ejemplar que la mayoría de ellos ha mantenido en el cumplimiento de los plazos y en la defensa de su independencia. Y, de otra, a la afortunada circunstancia de que el número de recursos, aunque considerable, no ha sido excesivamente elevado, gracias a la atonía de la economía española y del decreciente volumen de compras públicas en todos estos años de crisis. Sólo cabe desear que, cuando esta doble situación se altere, tanto por la recuperación de la inversión pública cuanto por la renovación de los miembros de los tribunales, se haga una apuesta por mantener los niveles de calidad ahora conseguidos: reforzando, de una parte, la composición personal de los tribunales, hoy ya en exceso reducida, y resistiendo la tentación de proveer las vacantes por funcionarios más pastueños o sensibles a los intereses de los órganos de contratación.

13 Sentencias de 15 de mayo de 2003, Comisión c. Reino de España, C-214/00, y de 3 de abril de 2008, Comisión c. Reino de España, C-444/06. 


\section{LOS OBJETIVOS PERSEGUIDOS Y SU FRACASO}

A la luz de todas estas innovaciones, es lícito preguntarse si eran necesarias. Pero, antes de ello, ha de partirse de un hecho, ineludible e incuestionable, cual es la profunda insatisfacción con el marco legislativo que vengo escuchando, desde hace mucho tiempo, a responsables políticos y funcionarios técnicos encargados de la gestión de los procedimientos. Todos ellos coinciden en la lamentación de que la legislación de contratos públicos, además de prolija y de una considerable complicación, supone un obstáculo considerable para el correcto desempeño de las funciones que han de realizarse con la colaboración de contratistas privados; impone una lentitud incompatible con la rápida ejecución de las tareas administrativas; es de difícil interpretación; suscita riesgos de incumplimiento, con posibles consecuencias penales; $y$, sobre todo, mecaniza en exceso la selección del contratista, obligando a elegir muchas veces al que se sabe de antemano menos adecuado. Y, añaden, todos estos obstáculos no se han allanado con la transposición de las normas comunitarias, sino que se han incrementado.

Estas quejas son sinceras y apuntan a problemas muy serios. ¿Habrán de soportarse, en aras de objetivos más relevantes? A mi juicio, la respuesta es negativa.

\section{El objetivo del mercado único}

El primero y más importante de ellos, en lo que afecta a la normativa comunitaria, consistió en la creación de un mercado único, europeo, de compras públicas; un objetivo que se ha saldado con un rotundo fracaso.

En efecto: basta echar una ojeada al Registro público de contratos para comprobar que la inmensa mayoría de estos se han adjudicado a empresas españolas; y lo mismo sucede en los restantes países de la Unión. La participación de empresas comunitarias en licitaciones de países ajenos al propio se ha producido, aunque en grado escaso, a través de vías que nada tienen que ver con las ofrecidas por la legislación de contratos: integrándose en UTEs licitadoras como aportantes de tecnología o de financiación, creando filiales en España, adquiriendo sociedades en nuestro país o asociándose con algún partner local provisto de buenos contactos con las autoridades adjudicadoras. Los mercados de compras públicas siguen siendo extraordinariamente cerrados: no tanto por razones de corrupción o connivencia, que también las hay, sino por la desconfianza que suscitan a los responsables políticos las empresas 
ajenas o extrañas; la ejecución de cualquier contrato requiere un alto grado de flexibilidad y de interlocución entre la Administración y el contratista, que deben compartir un extenso catálogo de valores implícitos compartidos, un amplio conjunto de pautas culturales que las empresas extranjeras desconocen.

\section{La lucha contra la corrupción}

Aunque no mencionado expresamente - hubiera sido políticamente incorrecto-, este ha constituido un objetivo al que han pretendido servir tanto las Directivas comunitarias como las propias ocurrencias del legislador interno: principalmente, mediante la objetivación máxima de los criterios de adjudicación y el refuerzo de los sistemas procedimentales de garantía y objetividad.

En este orden de cosas, los magros resultados conseguidos están también a la vista, como demuestra la escandalosa crónica judicial que los medios vienen sirviéndonos en los últimos años. Todas las sofisticadas estructuras normativas ideadas para eliminar los incentivos a la corrupción no han servido de nada, porque hay mil formas de eludir la competencia entre empresas, de falsear los precios y de predeterminar la elección de los contratistas, sorteando los criterios objetivos de adjudicación. La llamada corrupción es un mal tan viejo como la humanidad, que existe en todos los países en mayor o menor grado (incluso en los teóricamente más avanzados o democráticos), y cuyo nivel relativo no depende en absoluto de la regulación de los contratos públicos, sino de otros elementos ambientales como el régimen de financiación de los partidos políticos y su transparencia, el nivel de profesionalidad, preparación y retribución de los responsables públicos, los sistemas de control a posteriori de los supuestos de enriquecimientos de origen opaco, y la ética general de la población en cuanto al manejo escrupuloso de los fondos presupuestarios. Se trata de un fenómeno complejísimo, transversal a todos los gobiernos, países y regímenes políticos, y que es absurdo intentar yugular con medidas procedimentales simplonas y arbitristas, como las que establece la normativa de contratos públicos, que sirven de muy poco: estoy íntimamente convencido de que el nivel de corrupción que existe en este sector, en España y en cualquier otro país de la Unión, no sería mayor si no disfrutáramos de esta abrumadora legislación de contratos.

Y esto es así porque el diseño de los criterios de adjudicación de los contratos (aunque no sea el vehículo más frecuente de la comisión 
de ilegalidades) intenta conciliar dos objetivos incompatibles: su objetivación y la elección de mejor oferta. El artículo 150 del TRLCSP es un ejemplo paradigmático de racionalización inútil: en su preocupación por evitar los supuestos de adjudicaciones arbitrarias, se ordena que la valoración de las proposiciones de los licitadores ha de realizarse atendiendo "a criterios directamente vinculados al objeto del contrato" (lo cual es una soberana obviedad, por cierto). Y a esta obviedad sigue una larguísima enumeración, ejemplificativa, de conceptos rigurosamente indeterminados:

[...] la calidad, el precio, la fórmula utilizable para revisar las retribuciones ligadas a la utilización de la obra o a la prestación del servicio, el plazo de ejecución o entrega de la prestación, el coste de utilización, las características medioambientales o vinculadas con la satisfacción de exigencias sociales que respondan a necesidades, definidas en las especificaciones del contrato, propias de las categorías de población especialmente desfavorecidas a las que pertenezcan los usuarios o beneficiarios de las prestaciones a contratar, la rentabilidad, el valor técnico, las características estéticas o funcionales, la disponibilidad y coste de los repuestos, el mantenimiento, la asistencia técnica, el servicio postventa u otros semejantes.

Si dejamos a un lado algunos criterios de naturaleza típicamente populista, los restantes son, por así decir, indiscutibles. Pero su juego conjunto conlleva dos efectos: primero, la irrealidad de los pliegos de prescripciones técnicas y de las ofertas; los primeros, porque, cuando concretan dichos criterios, definen un escenario ideal y completamente alejado de la pedestre realidad de las cosas; un escenario que fuerza a las empresas licitadoras a confeccionar una oferta igualmente idílica y escasamente creíble (y cuya elaboración, además, requiere un esfuerzo y unos costes desproporcionados, que luego se intentan repercutir en el precio). Huelga decir que todos estos criterios, que deberían presidir también la ejecución de cada contrato, se esfuman tras la adjudicación. Y segundo, que la utilización conjunta de todos o de varios de estos criterios conduce a un sistema de valoración prácticamente discrecional: no solo por la presencia de factores de objetivación imposible (¿qué son «el valor técnico»o «las características estéticas o funcionales»?), sino por su misma multiplicidad. Dicho de manera más directa, es mucho más fácil trazar, en los pliegos, el retrato robot del licitador deseado utilizando catorce criterios puntuables que si sólo se utilizan dos o tres.

Toda esta regulación constituye un perfecto ejemplo de los monstruos de la razón: el esfuerzo por la máxima objetivación lleva al máximo nivel de subjetividad y discrecionalidad. 


\section{La unificación de las legislaciones}

Aunque de manera no abiertamente declarada (las Directivas no son el instrumento idóneo para ello), la normativa comunitaria ha perseguido, con toda evidencia, unificar las legislaciones de los Estados miembros. Pero la forma de intentar conseguirlo me parece completamente inadecuada.

Es inadecuado porque, como antes señalé, el contenido de las Directivas comunitarias es casi exclusivamente procedimental, como lo es la propia legislación española. Y las normas comunes de procedimiento chocan abiertamente con la diversidad irreductible de las reglas básicas que, en cada Estado miembro, regulan los poderes de las Administraciones en las relaciones jurídicas que entablan con los particulares; reglas cuya unificación el derecho comunitario no tiene capacidad de emprender. No hay posibilidad razonable de unificar los procedimientos de contratación si las normas vertebrales reguladoras del procedimiento administrativo general no son las mismas, o muy similares en todos los países.

Y el mismo efecto se produce ante la falta de unificación de las reglas de fondo que, en el derecho privado, regulan los contratos paralelos a los administrativos. Creo inútil intentar unificar la regulación de los contratos de obras, por ejemplo, cuando la forma en que se concibe el arrendamiento de obra, en los códigos y en la jurisprudencia civil de los países pertenecientes a la familia romano-germánica, es muy distinta de la configuración que tiene en los países de common law.

\section{La agilización de los procedimientos}

Los considerandos de todas las Directivas afirman — sin excesivo énfasis- perseguir la reducción de los tiempos de preparación y ejecución de las licitaciones. Este optimismo carece de toda justificación objetiva, desde el momento en que los procedimientos, en contra de toda lógica de eficacia, se han ido reformando sucesivamente en el sentido de una complicación y sofisticación crecientes, que dilata el tiempo que media entre la decisión de contratar y la fecha de comienzo de la ejecución efectiva de cada contrato. El testimonio de todos los titulares de órganos de contratación es unánime: en la actualidad, el período normal de tramitación comprendido entre la decisión (política) de contratar y la formalización del contrato es dos o tres veces superior al de hace veinte años. Salvo supuestos de radical optimismo antropológico, es impensable que alguien pudiera suponer que las nuevas normas permitirían acortar los tiempos de tramitación. 
Los factores determinantes de la ralentización de los procesos de licitación son múltiples, pero tres son los más importantes. Primero, la complejidad de los trámites de preparación del contrato, especialmente los referidos a la elaboración y contenido del proyecto en el contrato de obras (artículo 123 del TRLCSP) y, sobre todo, del estudio de viabilidad y anteproyecto de construcción en el contrato de concesión de obra pública (artículos 128 y 129) y del documento de evaluación previa y del programa funcional en el contrato de colaboración público/privado (artículos 134 y 135). Dicha complejidad no sólo supone una considerable inversión de tiempo previo al inicio de las actuaciones, sino que tiene un alto coste de ejecución que, cuando no puede ser absorbido directamente por los servicios técnicos de la Administración, ha de ser externalizado, lo que supone un gasto adicional al del contrato principal, que encarece seriamente éste. Segundo, la amplitud de los plazos de celebración de los trámites sucesivos de la licitación: en el procedimiento abierto - por tomar solo un ejemplo- estos son los de presentación de proposiciones (cincuenta y dos días: artículo 159.1 TRLCSP), apertura de las proposiciones (un mes: artículo 160.1), adjudicación (dos meses: artículo 161.2) y formalización (quince días hábiles: artículo 156.3); cinco meses mínimo, salvo los de presentación de proposiciones. Y tercero, la escasez de dotación de efectivos de los servicios administrativos de contratación, que fuerza en muchos casos a exceder notablemente los plazos antes indicados. Si a los mismos se añade el tiempo que ha de emplearse en los trámites de preparación del contrato, antes mencionados, no es exagerado decir que el plazo real que media entre la iniciativa política de celebrar un contrato y, por así decir, firmarlo, difícilmente es inferior a un año. Desde la perspectiva de la empresa privada, dicho plazo es incomprensible; pero para cualquier responsable político, cuya perspectiva vital no excede los límites de una legislatura, es una eternidad.

\section{CONCLUSIÓN}

A la vista de las páginas anteriores, parece casi innecesario resumir la opinión de su autor acerca de la insatisfacción profunda que causa, en su conjunto, la vigente normativa de contratos, cuyas partes disfuncionales superan, con mucho, a sus aspectos positivos y que la normativa comunitaria no ha hecho, salvo excepciones, sino empeorar. Su evolución ha seguido una senda de continuo incremento en extensión y complejidad, generando unos cuerpos legales enormes, confusos e inextricables, en el que muy pocos saben orientarse, y que pronto serán 
sustituidos por otros más inaccesibles aún: la lectura del Anteproyecto que se halla en espera de un nuevo Parlamento y de un nuevo gobierno no ofrece esperanza alguna de mejora; es, dicho brevemente y con todo respeto a sus redactores, más de lo mismo.

Esta legislación ha generado dificultades extraordinarias: un ambiente de inseguridad jurídica, la eliminación virtual de la jurisprudencia como fuente de interpretación y de cobertura de lagunas y, sobre todo, la aparición de niveles crecientes de incumplimiento y desconocimiento de la normativa, con el riesgo asociado, para los gestores públicos, de ser imputados por supuestos delitos de prevaricación. Y, en contrapartida, no ha logrado un grado de consecución mínima de los objetivos que supuestamente ha perseguido: no ha conseguido crear un auténtico mercado único de compras públicas, no ha disminuido un ápice el nivel de corrupción; y, desde luego, no ha agilizado los procedimientos de contratación, sino todo lo contrario.

Las sociedades europeas, obligadas a vivir en una economía global, no pueden permitirse el lujo de tener unas estructuras públicas maniatadas por unas normas de contratación tan rígidas, sólo inspiradas en una regla de temerosa prevención del mal uso de los fondos públicos y de su apropiación ilegítima por operadores privados. Hemos creado, en suma, para alojar el mercado de compras públicas, una suerte de hogar enorme e inhóspito, incómodo, constrictivo y complicado de entender y gestionar que explica, aunque no justifique, los intentos de salirse del mismo; y, para mayor pesimismo, un hogar que se ha terminado convirtiendo en una suerte de establecimiento penitenciario, donde son severamente abortados todos los intentos de fuga, y que no tiene perspectiva alguna de desaparecer.

Serán muchos, sin duda, los que no compartan esta valoración global, a la que seguramente tildarán de catastrofista. No creo que ello sea justo: pero, aunque lo fuera, estaría justificada subjetivamente en el desaliento generado por los estériles esfuerzos y las cuantiosas horas malgastadas en pugnar por entender, aprender e interpretar profesionalmente estas leyes. A las alturas de los tiempos en que nos encontramos, me parece indiscutible que los juristas, las Administraciones y los contratistas no nos merecemos una normativa tan manifiestamente mejorable. 